\title{
Yüksek Öğrenim Enstitüleri İçin Marka Kimliği Ölçeğinin Türkçeye Uyarlanması: Güvenirlik ve Geçerlilik Çalışması
}

\section{The Turkish Adaptation of the Brand Identity Scale for Higher Education Institutions: A Validity and Reliability Study}

\section{Öz:}

Zeki YÜKSEKBİLGILLI

$\mathrm{Bu}$ araştırmada yüksek öğrenim enstitülerinin marka kimliğini ölçmek üzere geliştirilen Yüksek Öğrenim Enstitüleri İçin Marka Kimliği Ölçeğinin (YÖKMKÖ) Türkçeye uyarlanması amaçlanmaktadır. Araştırmaya kolayda örnekleme ile seçilen, 660 denek katılmıştır $(\mathrm{n}=660)$. Araştırma kapsamında ölçme aracı Türkçeye çevrilmiş̧ir. Ölçme aracının yapı geçerliği Açımlayıcı Faktör Analizi ve Doğrulayıcı Faktör Analizi (DFA) ile test edilmiştir. Sonuç olarak 33 maddelik ve 2 boyutlu ölçme aracı, Türk araştırmacıların kullanımına hazır hâle getirilmiştir.

Anahtar Sözcükler: Yüksek Öğrenim Enstitüleri, Marka Kimliği Ölçeği, Marka Ölçeği, Ölçek Uyarlama, Türkçe, Yüksek Öğrenim Hizmetleri Pazarlama

\begin{abstract}
:
In this study, the author have aimed to adapt the Brand Identity Scale (BIS) developed to measure higher education institutes' brand identity to Turkish. A total of 660 surveyers from Turkey were selected using convenient sampling to participate in this study $(\mathrm{n}=660)$. During the course of this study, the BIS was first translated into Turkish. The construct validity of the FQS was tested using exploratory (EFA) and confirmatory factor analysis (CFA). In conclusion, an instrument consisting of 33 items and 2 subscales was prepared for Turkish researchers.
\end{abstract}

Keywords: Higher Education Institution, Brand Identity Scale, Brand Scale, Scale Adaptation, Turkish, Higher Education Services Marketing

\footnotetext{
*Yrd. Doç. Dr. Zeki Yüksekbilgili, Nişantaşı Üniversitesi, yuksekbilgili@gmail.com
} 


\section{Araștırma}

\subsection{Araștırmanın Amacı}

Bu araştırmada yüksek örenim enstitülerinin marka kimliğini ölçmek üzere geliştirilen Yüksek Öğrenim Enstitüleri İçin Marka Kimliği Ölçeğinin (YÖKMKÖ) Türkçeye uyarlanması amaçlanmaktadır. Bu amaçla öncelikle yazarlardan ölçeğin uyarlanabilmesi için izin istenmiş, yazılı iznin 20-02-2016 tarihinde alınmasından sonra uyarlama çalışmalarına başlanmıştır.

\subsection{Orïinal Marka Beğgenilirlik Ölçeğinin Özellikleri}

Mei Teh Goi, Chai Lee Goi \& David Wong (2014) tarafından geliştirilen orijinal YÖKMKÖ, iki faktörlü bir yapıya sahiptir. Bunlar görsel ve sözlü olarak tanımlanmıştır.

Orijinal YÖKMKÖ'de 2 farklı boyutu ölçmek için toplam 33 soru bulunmaktadır. Orijinal ölçekte bulunan sorular aşağıdaki tabloda gösterilmiştir;

Bă̆ll bulunduğum enstitü,

Tablo 1: Orijinal MBÖ’ye ait sorular

\begin{tabular}{|c|c|}
\hline $\begin{array}{c}\text { Soru } \\
\text { No }\end{array}$ & Soru \\
\hline 1 & tarafindan yapılan reklamlar eğitim kurumunun odak noktasını yansıtır. \\
\hline 2 & güvenilir eğitim kurumu temsilcilerine sahiptir. \\
\hline 3 & faydall bir internet sitesine sahiptir. \\
\hline 4 & ikna edici referanslara sahiptir. \\
\hline 5 & aktif mezunlar derneğine sahiptir. \\
\hline 6 & anlamlı sponsorluklar ile eğitim kurumunun odak noktasını yansıtır. \\
\hline 7 & tarafindan eğitici seminerler, söyleşiler gerçekleştirilmektedir. \\
\hline 8 & anlamlı sosyal katkllarda bulunur. \\
\hline 9 & ile ilgili gazete ve dergilerde ikna edici yazılar bulunmaktadır. \\
\hline 10 & cazip tanıtım materyallerine (yer işaretleri, broşürler...) sahiptir. \\
\hline 11 & çekici ilanlara ve flamalara sahiptir. \\
\hline 12 & kusursuz kampüs içi tesislere sahiptir. \\
\hline 13 & kusursuz kampüs alt yapısına sahiptir. \\
\hline 14 & faydalı danışmanlık hizmetleri (finans, kariyer, kurslar vb. konularda) sunar. \\
\hline 15 & kusursuz eğitim ve yönetim kadrosuna sahiptir. \\
\hline 16 & ögrencilere saygl ve sevgiyle yaklaşan kadroya sahiptir. \\
\hline 17 & çalışma odağını yansıtan bir eğitim kurum ismine sahiptir. \\
\hline 18 & eğitim kurumu adını yansitan bir logoya sahiptir. \\
\hline 19 & güçlü bir eğitim kurumu sloganına sahiptir. \\
\hline 20 & geniş çapll ders seçenekleri sunar. \\
\hline 21 & belirli alanlarda uzmanlaş̧mıştır. \\
\hline 22 & yaygın ve tanınan ders seçenekleri sunar. \\
\hline 23 & kaliteli bir ders programı sunar. \\
\hline 24 & programları için makul fiyatlar sunar. \\
\hline 25 & marka değgeri yüksektir. \\
\hline 26 & üstün misyon ve vizyona sahiptir. \\
\hline 27 & profesyonel bir yönetim sistemine sahiptir. \\
\hline 28 & fark edilen bir üniversite kimliğine sahiptir. \\
\hline 29 & görevlerinde iyi ĕ̆itilmiş çalışanlara sahiptir. \\
\hline 30 & bilgili ve yetenekli çalışanlara sahiptir. \\
\hline 31 & içerisinde sunulan hizmetler birbirleri ile koordinelidir. \\
\hline 32 & adil ve standardize edilmiş sistemlerle yönetilmektedir. \\
\hline 33 & kaliteli bir ders geçiş notu oranı kullanmaktadır. \\
\hline
\end{tabular}

Ölçek 5'li Likert tipinde düzenlenmiştir bunlar; 5- Kesinlikle Katılıyorum, 4- Katılıyorum, , 3- Kararsızım, 2Katılmıyorum ve 1- Kesinlikle katılmıyorum olarak puanlanmaktadır. Ölçekteki tüm maddeler pozitif olarak puanlanmaktadir.

Goi, Goi ve Wong (2014) tarafından geliştirilen YÖKMKÖ ait geçerlilik değeri 0,96 olarak ölçümlenmiştir. Kalaycı $(2008,405)$ 'ya göre Cronbach's Alpha katsayısına bağlı olarak ölçeğin güvenilirliği aşadörtğıdaki gibi yorumlanmaktadir:

• $0.00 \leq \alpha<0.40$ ise ölçek güvenilir değildir, 
- $0.40 \leq \alpha<0.60$ ise ölçeğin güvenilirliği düşük,

- $0.60 \leq \alpha<0.80$ ise ölçek oldukça güvenilir, ve

• $0.80 \leq \alpha<1.00$ ise ölçek yüksek derecede güvenilir bir ölçektir.

Ölçek ve alt faktörlerine ilişkin elde edilen Cronbach Alpha değerleri ölçekte yer alan maddelerin geçerliklerinin yüksek olduğu ve ölçekte yer alan maddelerin ölçek içinde aynı davranışı ölçmeye yönelik maddeler oldukları şeklinde yorumlanabilir.

\section{Yöntem}

\section{1. Çeviri Çalışması}

YÖKMKÖ’nün İngilizce orijinalinde yer alan maddeler sosyal bilimler konusunda uzmanlaşmış dört akademisyen ve dört pazarlama uzmanı tarafından incelenip Türkçeye çevrilmiştir. Birbirinden bağımsız olarak yapılan bu çeviriler, bir arada değerlendirilmiş ve her bir madde için en uygun çeviri metni seçilmiştir. Daha sonra seçilen metinler İngiliz Dili ve Edebiyatı alanında uzman iki akademisyen tarafından yeniden İngilizceye çevrilmiş ve orijinal soru formu ile karşılaştırılmıştır. En son aşamada ölçek için hazırlan Türkçe formu, Türk Dili ve Edebiyatı alanında uzman iki akademisyen tarafından biçimsel olarak Türkçe imla ve anlatım kurallarına uygunluklarına göre incelendikten sonra uygulamaya hazır hale getirilmiştir.

\subsection{Verilerin Analizi}

Verilerin analizinde, SPSS (Statistical Package Program for Social Science) 15.0 ve IBM SPSS AMOS 22.0 programları kullanılmıştır.

\subsubsection{Araştırmanın Betimsel İstatistikleri}

Araştırma kapsamında 660 katılımcı ile anket çalışması yapılmıştır. Katılımcıların demografik özellikleri aşağıdaki tabloda özetlenmiştir;

Tablo 2. Katılımcıların Demografik Özellikleri

\begin{tabular}{|c|c|c|c|}
\hline \multirow{3}{*}{ Cinsiyet } & & $N$ & $N \%$ \\
\hline \multirow{5}{*}{ Yaş } & Kadın & 280 & 42,4 \\
\cline { 2 - 4 } & Erkek & 380 & 57,6 \\
\cline { 2 - 4 } & $>25$ & 40 & 6,1 \\
\cline { 2 - 4 } & $25-30$ & 150 & 22,7 \\
\cline { 2 - 4 } & $31-35$ & 150 & 22,7 \\
\cline { 2 - 4 } & $36-40$ & 130 & 19,7 \\
\cline { 2 - 4 } & $41-45$ & 60 & 9,1 \\
\cline { 2 - 4 } & $46-50$ & 70 & 10,6 \\
\cline { 2 - 4 } & $50>$ & 60 & 9,1 \\
\hline \multirow{4}{*}{ Program } & Yüksek lisans & 470 & 28,8 \\
\hline
\end{tabular}

\subsection{Faktör Analizleri}

\subsection{1. Ölçeklerin Doğrulayıcı Faktör Analizi Sonuçları}

Doğrulayıcı faktör analizi ve yapısal eşitlik modellerinde, model uyumunun değerlendirilmesinde Ki-kare istatistiği (X2), ki-kare istatistiğinin serbestlik derecesine oranı ( $\left.\mathrm{X}^{2} / \mathrm{sd}\right)$, tahmin edilen bireysel parametre tahminlerinin istatistiksel anlamlılığı (t değeri), "kalıntılara dayanan" (SRMR, GFI), "bağımsız modele dayanan" (NFI, NNFI, CFI) ve "yaklaşık hataların ortalama karekökü (RMSEA)" olarak sınıflandırılan uyum indeksleri kullanılmaktadır. Uyum indekslerinin kabul edilebilirlik ve iyi uyum değerlerine Tablo 3'de yer verilmiştir (Bayram 2010; Sümer 2000; Raykov 1997). Doğrulayıcı faktör analizi ve hipotezlerin test edildiği yol analizi uygulamasında göstergelerin tümünün ilgili faktörde yüksek faktör yüklerine (Std. $\beta$ ) sahip olmasına, bireysel parametre tahminlerinin istatistiksel anlamlılı̆̆ını gösteren $t$ değerlerinin, anlamlı olmasına, hata varyanslarının yüksek olmamasına, faktör yüklerinin ve faktörler arası korelasyonun 0,90’ın altında olmasına dikkat edilmiştir. Faktörler arası korelasyonun aşırı yüksek olması ilgili faktörlerin birleştirilmesi gerektiği anlamını taşımaktadır (Çokluk, Şekercioğlu, Büyüköztürk 2010; Bayram 2010; Meydan ve Şeşen 2011). 
Tablo 3. Doğrulayıcı Faktör Analizi Uyum İndeksleri

\begin{tabular}{|c|c|c|}
\hline & \multicolumn{2}{|c|}{ Uyum Değerleri } \\
\hline Model Uyum İndeksleri & Kabul Edilebilir & $\dot{I y i} /$ Çok $\dot{I} y i$ \\
\hline$p$ & $p<0,05$ & $p<0,01$ \\
\hline$X^{2} / s d$ & $X^{2} / s d<5$ & $X^{2} / s d<3$ \\
\hline RMSEA & $0,05 \leq R M S E A \leq 0,08$ & $0,00 \leq R M S E A \leq 0,05$ \\
\hline SRMR & $0,05 \leq S R M R \leq 0,08$ & $0,00 \leq S R M R \leq 0,05$ \\
\hline GFI & $0,90 \leq G F I \leq 0,95$ & $0,95 \leq G F I \leq 1,0$ \\
\hline NFI & $0,90 \leq N F I \leq 0,95$ & $0,95 \leq N F I \leq 1,0$ \\
\hline NNFI & $0,90 \leq N N F I \leq 0,95$ & $0,95 \leq N N F I \leq 1,0$ \\
\hline CFI & $0,90 \leq C F I \leq 0,95$ & $0,95 \leq C F I \leq 1,0$ \\
\hline
\end{tabular}

Güvenirlik çalışması kapsamında madde toplam korelasyonu ve Cronbach Alpha testleri uygulanmıştır. Maddetoplam korelasyonu, test maddelerinden alınan puanlar ile testin toplam puanı arasındaki ilişkiyi açıklar. Maddetoplam korelasyonunun pozitif ve yüksek olması, maddelerin benzer davranışları örneklediğini gösterir ve testin iç tutarlığının yüksek olduğunu gösterir. Genel olarak madde-toplam korelasyonu 0,30 ve daha yüksek olan maddelerin bireyleri iyi derecede ayırt ettiği, 0,20-0,30 arasında kalan maddelerin zorunlu görülmesi durumunda teste alınabileceği söylenebilir. Cronbach Alpha katsayısının 0,70'in üzerinde olması beklenir. Cronbach Alpha ve madde toplam korelasyonu, maddelerin bireyleri ölçülen davranış bakımından ne derece ayırt ettiğini gösterir (Büyüköztürk 2011, 171-172).

\subsubsection{Doğrulayıcı Faktör Analizi Sonuçları}

Ölçeğin doğrulayıcı faktör analizi başlangıcı ve sonucunda elde edilen uyum indekslerine değerlerine Tablo 2'de yer verilmiştir. Ölçeğin daha önce geliştirilmiş yapısına uygun madde faktör ilişkisi kurularak ilk doğrulayıcı faktör analizi yapılmıştır. Analiz öncesi değişkenlerin normal dağılımları çarpıklık katsayısı ile incelenmiştir. 12 değişken ve 2 faktör ile yapılan doğrulayıcı faktör analizi ilk sonuçlarına göre model uyumunun sağlanamadığı, faktör yükü 0,90 ve üzerinde olan iki değişken olduğu (kurum kültürü ve sistem/proses), ayrıca iki faktör arasındaki korelasyonun 0,92 ile oldukça yüksek olduğu tespit edilmiştir. Yapılan açımlayıcı faktör analizinde ise ölçekte özdeğeri 1'in üzerinde tek bileşen olduğu ve ilk bileşenin ikinci bileşene oranının 10 kat daha fazla olduğu tespit edilmiştir (Tablo 4, Şekil 1). Elde edilen bu sonuçlar ölçeğin tek faktörlü yapısının daha uygun olduğunu göstermektedir.

Tablo 4. Ölçeğin İlk DFA ve AFA Sonuçları

\begin{tabular}{|c|c|c|c|c|c|}
\hline & & & \multicolumn{2}{|c|}{ DFA } & AFA \\
\hline Model Uyum İndeksleri & $\begin{array}{c}\text { Uyum } \\
\text { Sonuçları }\end{array}$ & Değişkenler & $\begin{array}{c}F 1 \\
\text { Std. } \beta\end{array}$ & $\begin{array}{c}F 2 \\
\text { Std. } \beta\end{array}$ & $\begin{array}{c}F 1^{*} \\
\lambda\end{array}$ \\
\hline$X^{2} / s d$ & 16,25 & 1- Dağıtım kanalı $(D C)$ & 0,70 & & 0,73 \\
\hline RMSEA & 0,15 & 2- Kulaktan kulağa (WOM) & 0,77 & & 0,76 \\
\hline SRMR & 0,05 & 3- Halkla ilişkiler $(P R)$ & 0,82 & & 0,80 \\
\hline GFI & 0,81 & $\begin{array}{l}\text { 4- Tanitım materyalleri } \\
(P R)\end{array}$ & 0,79 & & 0,77 \\
\hline NFI & 0,87 & 5- Hizmet tesisleri $(P M)$ & & 0,75 & 0,79 \\
\hline NNFI & 0,85 & 6- Personel servisleri (SF) & & 0,79 & 0,81 \\
\hline CFI & 0,88 & 7- Marka adı (ES) & & 0,75 & 0,77 \\
\hline Faktör yük aralı̆̆ & $0,70-0,92$ & $\begin{array}{l}\text { 8- Ürün/temel hizmetler } \\
\text { (CS) }\end{array}$ & & 0,83 & 0,83 \\
\hline Boyutlar arası korelasyon & 0,92 & 9- Fiyat (Price) & & 0,72 & 0,73 \\
\hline$K M O$ & 0,93 & $\begin{array}{l}\text { 10- Kurum kültürü } \\
\text { (Culture) }\end{array}$ & & 0,92 & 0,92 \\
\hline Bartlett's $p$ & 0,000 & $\begin{array}{l}\text { 11- Eğitim/personel } \\
\text { geliștirme (Training) }\end{array}$ & & 0,83 & 0,82 \\
\hline $\begin{array}{c}\text { Özdeğerler } \\
\text { (ilk üç sirasıyla) }\end{array}$ & $\begin{array}{c}7,81 / 0,76 / 0 \\
68\end{array}$ & 12- Sistem/süreç (System) & & 0,91 & 0,91 \\
\hline Toplam Varyans (\%) & & & & & 65,05 \\
\hline
\end{tabular}

* Varimax döndürmesinde tek faktör elde edilmiştir. 


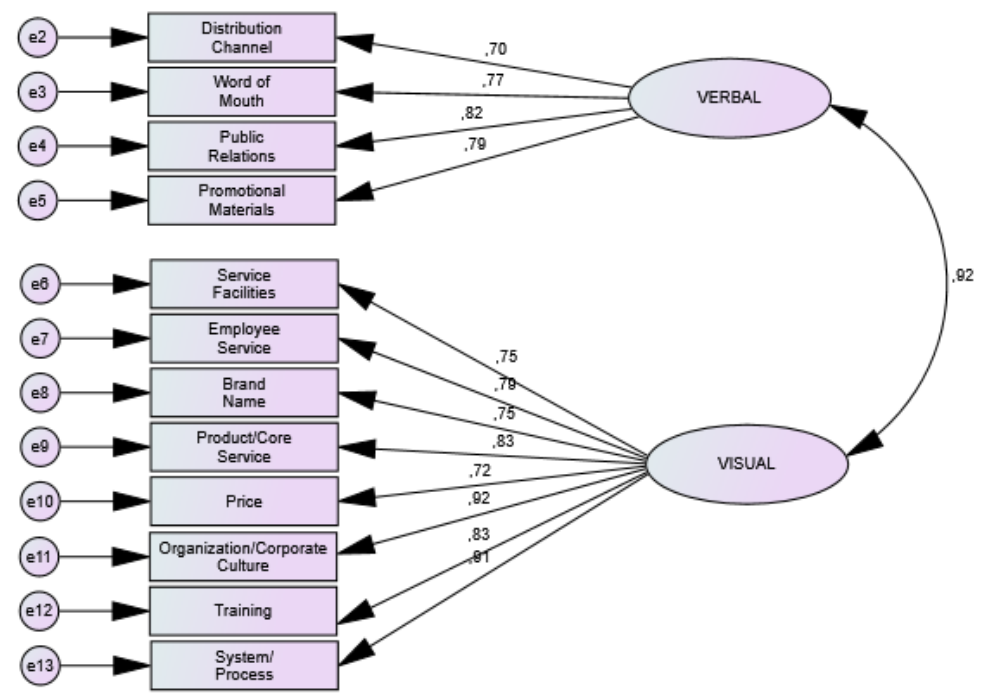

Şekil 1. İki Boyutlu Doğrulayıcı Faktör Analizi Diyagramı

Ölçeğin iki boyutlu orijinal yapısını korumak amacıyla öncelikle maddeler arasında kovaryans önerileri dikkate alınarak doğrulayıcı faktör analizi tekrarlanmış ancak madde faktör yüklerinde ve boyutlar arası korelasyonda düşme gözlenmemiştir. Faktör yükü yüksek iki değişken (kurum kültürü ve sistem) çıkarılarak işlemler tekrarlanmış, ancak iki boyut arasındaki yüksek korelasyonun ortadan kalkmadı̆̆ı gözlenmiştir. Bu nedenle ölçeğin tek faktörlü yapısının daha uygun olduğuna karar verilmiştir.

Yüksek faktör yüküne sahip değişkenler (kurum kültürü ve sistem) çıkarılmadan önce diğer değişkenlerle ilişki durumu incelenmiştir. Yapılan Pearson korelasyon analizinde kültür-marka adı $(r=0,82)$, kültür-sistem $(r=0,81)$ ve sistem-eğitim $(\mathrm{r}=0,86)$ arasında yüksek korelasyon olduğu tespit edilmiştir (Tablo 5).

Tablo 5. Değişkenler Arası Pearson Korelasyonu

\begin{tabular}{|c|c|c|c|c|c|c|c|c|c|c|c|c|}
\hline & 1 & 2 & 3 & 4 & 5 & \begin{tabular}{|c|}
6 \\
\end{tabular} & 7 & \begin{tabular}{|l|}
8 \\
\end{tabular} & 9 & 10 & 11 & 12 \\
\hline 1- Dă̆ıtım kanalı (DC) & 1,00 & $\begin{array}{c}0,57 \\
* *\end{array}$ & $\begin{array}{c}0,50 \\
* *\end{array}$ & $\begin{array}{c}0,53 \\
* *\end{array}$ & $\begin{array}{c}0,56 \\
* *\end{array}$ & $\begin{array}{c}0,58 \\
* *\end{array}$ & $0,56^{* *}$ & $\begin{array}{c}0,63 \\
* *\end{array}$ & $\begin{array}{c}0,48 \\
* *\end{array}$ & $\begin{array}{c}0,64 \\
* *\end{array}$ & $\begin{array}{c}0,54 \\
* *\end{array}$ & $\begin{array}{c}0,56 \\
* *\end{array}$ \\
\hline 2- Kulaktan kulağa (WOM) & & & $\begin{array}{c}0,64 \\
* *\end{array}$ & $\begin{array}{c}0,57 \\
* *\end{array}$ & \begin{tabular}{|c|}
0,67 \\
$* *$
\end{tabular} & $\begin{array}{c}0,51 \\
* *\end{array}$ & $\begin{array}{c}0,56 \\
* *\end{array}$ & $\begin{array}{c}0,60 \\
* *\end{array}$ & $\begin{array}{c}0,47 \\
* *\end{array}$ & $\begin{array}{c}0,71 \\
* *\end{array}$ & $\begin{array}{c}0,49 \\
* *\end{array}$ & $\begin{array}{c}0,61 \\
* *\end{array}$ \\
\hline 3- Halkla iliş̧kiler (PR) & & & & $\begin{array}{c}0,72 \\
* *\end{array}$ & $\begin{array}{c}0,65 \\
* *\end{array}$ & $\begin{array}{r}0,63 \\
* *\end{array}$ & $\begin{array}{c}0,53 \\
* *\end{array}$ & $\begin{array}{c}0,56 \\
* *\end{array}$ & $\begin{array}{c}0,50 \\
* *\end{array}$ & $\begin{array}{c}0,69 \\
* *\end{array}$ & $\begin{array}{c}0,60 \\
* *\end{array}$ & $\begin{array}{c}0,71 \\
* *\end{array}$ \\
\hline 4- Tanitim materyalleri $(P R)$ & & & & & $\begin{array}{r}0,57 \\
* *\end{array} \mid$ & $\begin{array}{c}0,62 \\
* *\end{array}$ & $\begin{array}{c}0,58 \\
* *\end{array}$ & $\begin{array}{c}0,53 \\
* *\end{array}$ & $\begin{array}{c}0,46 \\
* *\end{array}$ & $\begin{array}{c}0,60 \\
* *\end{array}$ & $\mid \begin{array}{c}0,59 \\
* *\end{array}$ & $\begin{array}{c}0,73 \\
* *\end{array}$ \\
\hline 5- Hizmet tesisleri (PM) & & & & & & {$\left[\begin{array}{c}0,65 \\
* *\end{array}\right.$} & $\begin{array}{c}0,56 \\
* *\end{array}$ & $\left|\begin{array}{c}0,61 \\
* *\end{array}\right|$ & $\begin{array}{c}0,48 \\
* *\end{array}$ & $\begin{array}{c}0,72 \\
* *\end{array}$ & $\begin{array}{c}0,55 \\
* *\end{array}$ & $\begin{array}{c}0,63 \\
* *\end{array}$ \\
\hline 6- Personel servisleri (SF) & & & & & & & $\begin{array}{c}0,62 \\
* *\end{array}$ & $\begin{array}{c}0,59 \\
* *\end{array}$ & $\begin{array}{c}0,52 \\
* *\end{array}$ & $\begin{array}{c}0,71 \\
* *\end{array}$ & $\begin{array}{c}0,70 \\
* *\end{array}$ & $\begin{array}{c}0,73 \\
* *\end{array}$ \\
\hline 7- Marka adı (ES) & & & & & & & & $\begin{array}{c}0,58 \\
* *\end{array}$ & $\begin{array}{c}0,56 \\
* *\end{array}$ & $\begin{array}{c}0,73 \\
* *\end{array}$ & $\begin{array}{c}0,58 \\
* *\end{array}$ & $\begin{array}{c}0,66 \\
* *\end{array}$ \\
\hline 8- Ürün/temel hizmetler (CS) & & & & & & & & & $\begin{array}{c}0,65 \\
* *\end{array}$ & $\begin{array}{c}0,82 \\
* *\end{array}$ & $\begin{array}{c}0,68 \\
* *\end{array}$ & $\begin{array}{c}0,76 \\
* *\end{array}$ \\
\hline 9- Fiyat (Price) & & & & & & & & & & $\begin{array}{c}0,70 \\
* *\end{array}$ & $\begin{array}{c}0,57 \\
* *\end{array}$ & $\begin{array}{c}0,66 \\
* *\end{array}$ \\
\hline 10- Kurum kültürü (Culture) & & & & & & & & & & & $\begin{array}{c}0,72 \\
* *\end{array}$ & $\begin{array}{c}0,81 \\
* *\end{array}$ \\
\hline 11- Eğitim / personel gelişstirme (Training) & & & & & & & & & & & & $\mid \begin{array}{c}0,86 \\
* *\end{array}$ \\
\hline 12- Sistem/süreç (System) & & & & & & & & & & & & 1 \\
\hline Kültür-Süreç & $\begin{array}{c}0,63 \\
* *\end{array}$ & $\begin{array}{c}0,69 \\
* *\end{array}$ & $\begin{array}{c}0,73 \\
* *\end{array}$ & $\begin{array}{c}0,69 \\
* *\end{array}$ & $\begin{array}{c}0,72 \\
* *\end{array}$ & $\begin{array}{c}0,75 \\
* *\end{array}$ & $\begin{array}{c}0,73 \\
* *\end{array}$ & $\begin{array}{c}0,83 \\
* *\end{array}$ & $\begin{array}{c}0,72 \\
* *\end{array}$ & & $\begin{array}{c}0,83 \\
* *\end{array}$ & \\
\hline
\end{tabular}


Kültür ve sistem değişkenlerindeki ifadeler incelendiğinde birbirine çok yakın anlamlar içerdikleri ve birleştirilebilecekleri gözlenmiştir. Bu nedenle her iki değişken birleştirilerek kültür_sistem değişkeni oluşturulmuştur. Yeni değişken ile yapılan DFA sonucunda kültür_sistem ortak değişkeninin faktör yükünün 0,99'a çıktığı gözlenmiştir. Yapılan açımlayıcı faktör analizinde de benzer şekilde yeni değişkenin faktör yükünün çok yüksek olduğu gözlenmiştir (Tablo 6, Şekil 2).

Tablo 6. Ölçeğin İkinci DFA ve AFA Sonuçları

\begin{tabular}{|c|c|c|c|c|}
\hline & & & DFA & AFA \\
\hline Model Uyum İndeksleri & $\begin{array}{c}\text { Uyum } \\
\text { Sonuçlart }\end{array}$ & Değişkenler & $\begin{array}{c}F 1 \\
\text { Std. } \beta\end{array}$ & $\begin{array}{c}F 1^{*} \\
\Lambda\end{array}$ \\
\hline$X^{2} / s d$ & 14,01 & 1- Dağıttım kanalı (DC) & 0,68 & 0,74 \\
\hline RMSEA & 0,14 & 2- Kulaktan kulağa (WOM) & 0,72 & 0,77 \\
\hline SRMR & 0,05 & 3- Halkla ilişkiler (PR) & 0,76 & 0,80 \\
\hline GFI & 0,85 & 4- Tanitım materyalleri $(P R)$ & 0,73 & 0,78 \\
\hline NFI & 0,90 & 5- Hizmet tesisleri (PM) & 0,75 & 0,79 \\
\hline NNFI & 0,88 & 6- Personel servisleri (SF) & 0,78 & 0,81 \\
\hline CFI & 0,90 & 7- Marka adı (ES) & 0,75 & 0,77 \\
\hline Faktör yük aralı̆ğ & $0,69-0,99$ & 8- Ürün/temel hizmetler (CS) & 0,83 & 0,82 \\
\hline Boyutlar arası korelasyon & 0,90 & 9- Fiyat (Price) & 0,72 & 0,72 \\
\hline$K M O$ & 0,93 & $\begin{array}{l}\text { 10- Ĕ̈̈tim/personel geliş̧tirme } \\
\text { (Training) }\end{array}$ & 0,83 & 0,81 \\
\hline Bartlett's $p$ & 0,000 & 11- Kültür_Süreç (KK_SIST) & 0,97 & 0,95 \\
\hline $\begin{array}{c}\text { Özdeğerler } \\
\text { (ilk üç sirasıyla) }\end{array}$ & $\begin{array}{c}7,07 / \\
0,75 / 0,63\end{array}$ & & & \\
\hline Toplam varyans (\%) & & & & 64,26 \\
\hline
\end{tabular}

* Varimax döndürmesinde tek faktör elde edilmiştir.

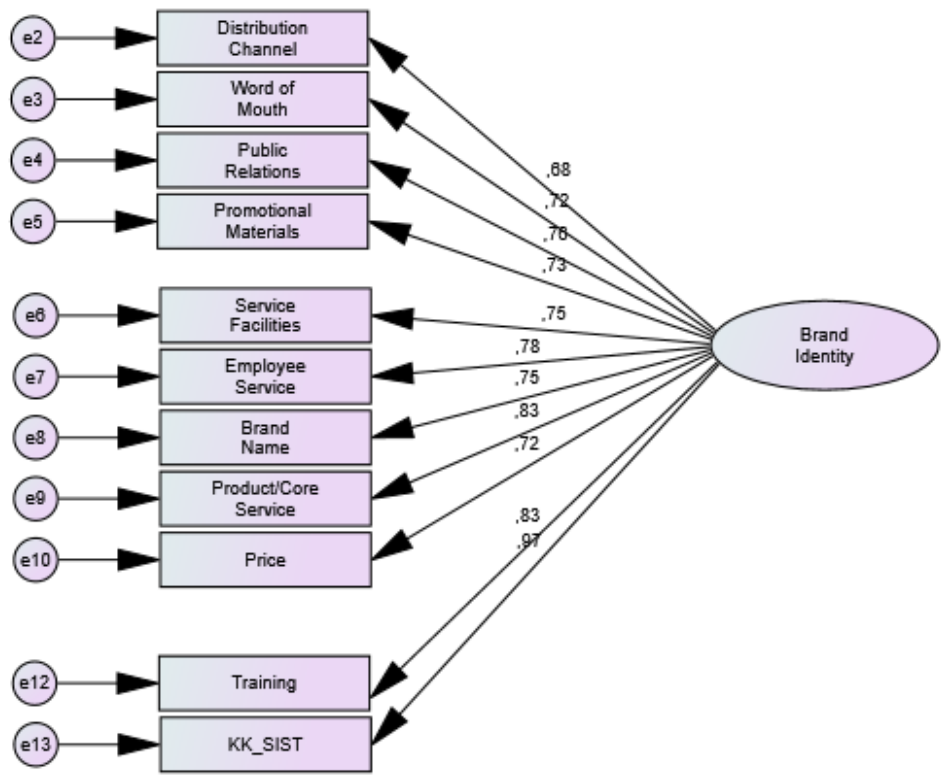

Şekil 2. İki Boyutlu Doğrulayıcı Faktör Analizi-2 Diyagramı

Kültür ve sistem değişkenlerinin yüksek faktör yükü sorunu çözülemediğinden değişkenlerin sırasıyla ölçekten çıkarılması yoluna gidilmiştir. Değişkenler çıkarıldığında model uyum indekslerinin kabul edilebilir seviyelere yakın olduğu, diğer değişkenlerin faktör yüklerinin uygun olduğu gözlenmiştir. Her iki değişken çıkarıldıktan sonra yapılan açımlayıcı faktör analizi sonucunda açıklanan toplam varyansın \%61,8 düzeyinde ve yeterli olduğu tespit edilmiştir (Tablo 7, Şekil 3). Model uyumunu iyileştirmek amacıyla modifikasyon önerileri gerçekleştirildikten sonra 10 değişkenden oluşan tek faktörlü yapının uyum indekslerinin kabul edilebilir seviyelere ulaştı̆̆ 1 ve modelin iyi uyum verdiği, faktör yüklerinin yeterli düzeyde olduğu, tüm maddeler için $t$ değerlerinin 0,01 düzeyinde anlamlı olduğu bulgusu elde edilmiştir. Ölçeğin Cronbach Alpha değeri 0,93 düzeyinde ve oldukça yüksek bulunmuştur. Maddelerin madde toplam korelasyonları 0,65 ile 0,76 aralığındadır (Tablo 7). 
Tablo 7. Ölçeğin Son Güvenirlik ve Geçerlik Analizi Sonuçları

\begin{tabular}{|c|c|c|c|c|c|c|}
\hline & & & DFA & & AFA & \\
\hline $\begin{array}{c}\text { Model Uyum } \\
\text { Indeksleri }\end{array}$ & $\begin{array}{c}\text { Uyum } \\
\text { Sonuçlart }\end{array}$ & Değişkenler & $\begin{array}{c}F 1 \\
\text { Std. } \beta\end{array}$ & $t$ & $\begin{array}{c}F 1^{*} \\
\lambda\end{array}$ & $r$ \\
\hline$X^{2} / s d$ & 4,63 & 1- Dağltım kanalı (DC) & 0,70 & & 0,75 & 0,69 \\
\hline RMSEA & 0,07 & $\begin{array}{l}\text { 2- Kulaktan kulăga } \\
(\text { WOM) }\end{array}$ & 0,78 & $18,52 * *$ & 0,77 & 0,71 \\
\hline$S R M R$ & 0,03 & 3- Halkla ilişkiler (PR) & 0,77 & $18,91^{* *}$ & 0,81 & 0,75 \\
\hline GFI & 0,96 & $\begin{array}{l}\text { 4- Tanitım materyalleri } \\
(P R)\end{array}$ & 0,73 & $18,10^{* *}$ & 0,79 & 0,73 \\
\hline NFI & 0,97 & 5- Hizmet tesisleri (PM) & 0,79 & $18,97 * *$ & 0,80 & 0,75 \\
\hline NNFI & 0,96 & 6- Personel servisleri (SF) & 0,83 & $20,20 * *$ & 0,82 & 0,77 \\
\hline CFI & 0,98 & 7- Marka adı (ES) & 0,73 & $18,01^{* *}$ & 0,77 & 0,72 \\
\hline $\begin{array}{l}\text { Faktör yük } \\
\text { aralığgl }\end{array}$ & $0,65-0,85$ & $\begin{array}{l}\text { 8- Ürün/temel hizmetler } \\
\text { (CS) }\end{array}$ & 0,77 & $20,94 * *$ & 0,82 & 0,76 \\
\hline$K M O$ & 0,93 & 9- Fiyat (Price) & 0,65 & $16,07 * *$ & 0,72 & 0,65 \\
\hline Bartlett's $p$ & 0,000 & $\begin{array}{l}\text { 10- Eğitim/personel } \\
\text { gelişstirme (Training) }\end{array}$ & 0,83 & $19,89 * *$ & 0,80 & 0,75 \\
\hline $\begin{array}{c}\text { Özdeğerler } \\
\text { (ilk üç sırasıyla) }\end{array}$ & $\begin{array}{c}6,18 / \\
0,73 / 0,61 \\
\end{array}$ & & & & & \\
\hline $\begin{array}{l}\text { Kovaryans } \\
\text { bağlantılart }\end{array}$ & \multicolumn{6}{|c|}{ DC-CS, WOM-SF, WOM-ES, WOM-Training, PR-PM, SF-Training, CS-Price } \\
\hline $\begin{array}{c}\text { Toplam varyans } \\
(\%)\end{array}$ & 61,84 & & & & & \\
\hline Cronbach Alpha & 0,93 & & & & & \\
\hline
\end{tabular}

* Varimax döndürmesinde tek faktör elde edilmiştir.

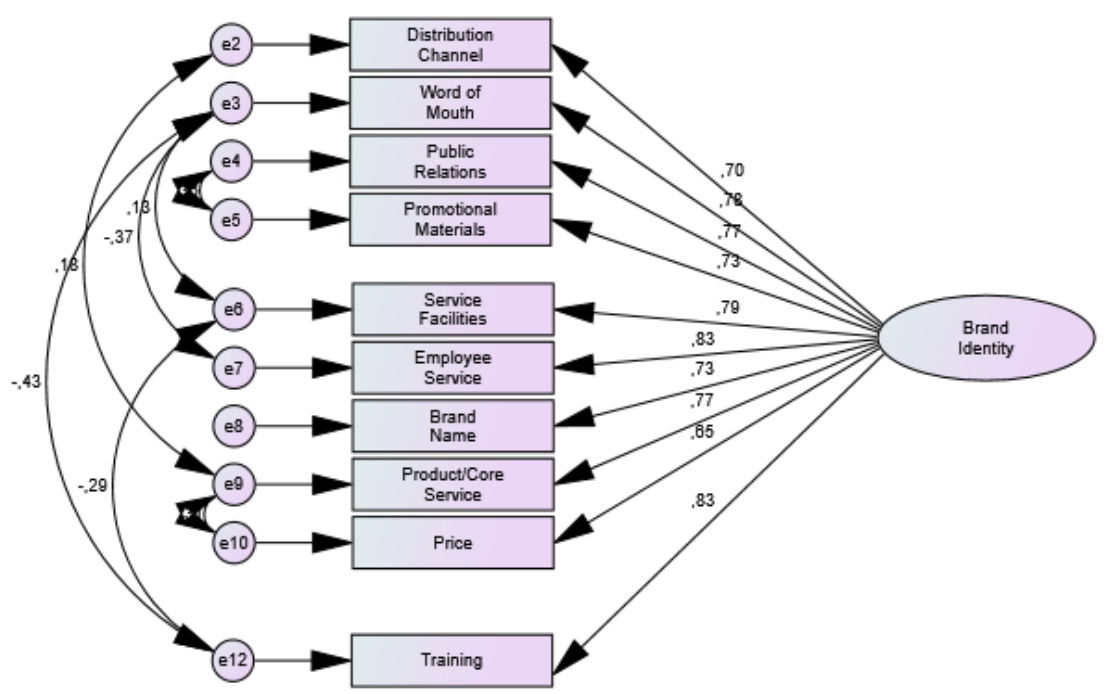

Şekil 3. Tek Boyutlu Doğrulayıcı Faktör Analizi Diyagramı

\section{Sonuç}

Ölçeğin güvenirlilik ve geçerlilik analiz sonuçları birlikte değerlendirildiğinde 33 madde ve iki alt boyutlu faktör yapısının uygun olduğu, ölçekteki maddelerin geçerliliklerinin yüksek olduğu, ve sonuç olarak Ek-1'de bulunan Türkiye’deki tüketiciler için uygulanabilir, güvenilir ve geçerli bir ölçek olduğu bulguları elde edilmiştir. 


\section{KAYNAKÇA}

Cem Harun Meydan ve Harun Şeşen 2011. Yapısal Eşitlik Modellemesi AMOS Uygulamaları. Detay Yayıncılık. Ankara.

Mei Teh Goi, Chai Lee Goi ve David Wong 2014. "Constructing a brand identity scale for higher education Institutions.” Journal of Marketing for Higher Education 24(1):59-74, http://dx.doi.org/10.1080/08841241.2014.906017

Nebi Sümer 2000. "Yapısal Eşitlik Modellemeleri: Temel Kavramlar ve Örnek Uygulamalar.” Türk Psikoloji Yazllarl, 3(6):49-74.

Nuran Bayram 2010. Yapısal Eşitlik Modellemesine Giriş. Ezgi Kitabevi. Bursa.

Ömay Çokluk, Güçlü Şekercioğlu ve Şener Büyüköztürk 2010. Sosyal Bilimler Iç̧in Çok Değişkenli Isstatistik. Pegem Yayınları. Ankara.

Şener Büyüköztürk 2011. Sosyal Bilimler İçin Veri Analizi El Kitabı (14. Bask1). Ankara: PEGEM Akademi.

Tenko Raykov 1997. "Scale reliability, Cronbach's Coefficient Alpha, and violations of essential tau-equivalence with fixed congeneric components.” Multivariate Behavioral Research 32, 329-353. 